\title{
Aplikasi Pembelajaran Huruf Hangeul Berbasis Android
}

\author{
Agung Baitul Hikmah', Yanti Apriyani ${ }^{2}$, Shelin Ayuni Purwandhani ${ }^{3}$ \\ 1,2,3 Sistem Informasi, Universitas Bina Sarana Informatika \\ e-mail: ${ }^{1}$ agung.abl@bsi.ac.id, ${ }^{2}$ yanti.ynp@bsi.ac.id, ${ }^{3}$ shelinpurwandhani@gmail.com
}

\begin{abstract}
Abstrak
Masuknya Budaya Korea Selatan ke Indonesia, ketertarikan terhadap budaya Korea Selatan membuat masyarakat Indonesia ingin mempelajari segala sesuatu tentang Korea Selatan, seperti mempelajari bahasanya, bahasa Korea sendiri memiliki huruf yang berbeda dengan huruf yang kita gunakan, huruf yang digunakan dalam bahasa Korea Selatan adalah huruf Hangeul. Dengan adanya perbedaan huruf ini membuat kesulitan dalam mempelajari bahasanya, karena sebelum mempelajari bahasanya kita harus mengetahui terlebih dahulu huruf dan cara membacanya. Tujuan dari penulisan penelitian ini adalah perancangan dan pengembangan aplikasi pembelajaran huruf Hangeul berbasis Android dengan menggunakan bahasa pemrograman C\# ( $C$ Sharp). Metode pengembangan perangkat lunak yang digunakan yaitu metode waterfall. Dengan kecanggihan teknologi komunikasi yang mana hasil dari penelitian ini mampu membuat perubahan dan menghasilkan inovasi, aplikasi pembelajaran huruf Hangeul berbasis Android ini menjadi solusi yang dapat memperbaiki kesulitan yang ada untuk mereka yang ingin belajar huruf Hangeul agar efisien dalam penggunaannya dan tidak menghabiskan banyak waktu dalam mempelajarinya.
\end{abstract}

\section{Kata Kunci : Huruf Hangeul, Aplikasi, Android, Korea Selatan}

\begin{abstract}
The entry of South Korean Culture into Indonesia, the interest in South Korean culture makes Indonesian people want to learn everything about South Korea, such as learning the language, Korean itself has letters that are different from the letters we use, the letters used in South Korean are Hangeul letters. This difference in letters makes it difficult to learn the language, because before learning the language we must know the letters first and how to read them. The purpose of writing this research was the design and development of Android-based Hangeul letter learning applications using the $C$ \# (C Sharp) programming language. The software development method used was the waterfall method. With the sophistication of communication technology where the results of this research were able to make changes and produce innovation, this Android-based Hangeul letter learning application was solution that could improve the existing difficulties for those who wanted to learn Hangeul letters to be efficient in their use and did not to spend much time in learning them.
\end{abstract}

\section{Keywords: Hangeul, Application, Android, South Korea}

\section{Pendahuluan}

Menurut (Korea Foundation, 2018) pada situs kbs.co.kr. Korea Selatan adalah negara maju yang terletak di Asia Timur. budaya Korea memiliki daya tarik di wilayah Asia maupun Internasional. budaya Korea tersebut telah masuk ke Indonesia dan belakangan ini segala sesuatu yang berhubungan dengan Korea Selatan menjadi perbincangan bagi masyarakat Indonesia mulai dari industri musik K-pop, K-drama, budaya, fashion, makanan, dan bahasanya. Korean Foundation menyebutkan bahwa hingga tahun 2017 fans halyu seluruh dunia melebihi 70 juta orang. Badan tesebut melakukan pendataan penyebaran halyu di 112 Negara, pada Desember 2017 disebutkan jumlah fans halyu paling banyak adalah di Asia yaitu 4,4 juta orang.

Ketertarikan terhadap budaya Korea membuat mereka ingin mempelajari tentang Korea seperti bahasanya. bahasa Korea sendiri memiliki huruf yang berbeda dengan 
huruf yang biasa kita gunakan, huruf yang digunakan untuk bahasa Korea adalah huruf Hangeul. Dengan perbedaan huruf ini membuat kesulitan dalam mempelajari bahasanya, karena sebelum mempelajari bahasanya kita harus mengetahui terlebih dahulu huruf dan cara membacanya.

$$
\text { Banyak yang mengambil }
$$

pembelajaran secara les privat tutor bahasa atau membeli buku panduan bahasa dan itu semua memakan biaya lebih, sehingga banyak peminat yang mencari sarana belajar secara gratis.

Untuk itu dibuatlah aplikasi pembelajaran huruf Korea (Hangeul) berbasis Android untuk memudahkan bagi mereka yang ingin belajar bahasa Korea. Dengan aplikasi ini belajar bahasa Korea akan lebih efisien dari segi biaya dan waktu karna bisa digunakan kapanpun dimanapun, dan juga menyenangkan.

Penulis akan memberi batasan terhadap aplikasi yang dibuat yaitu aplikasi ini hanya menampilkan huruf-huruf Hangeul, cara membacanya beserta audio suara huruf, contoh penulisan huruf dan terdapat latihan kuis yang dapat digunakan secara offline.

\section{Metode Penelitian}

\section{Metode Observasi (Observation) \\ Metode ini dilakukan secara langsung dengan pengamatan dan peninjauan oleh penulis pada aplikasi pembelajaran yang serupa.}

\section{Metode Studi Pustaka (Library Research)}

Metode studi pustaka digunakan penulis agar mendapatkan referensi baik dari buku ataupun dari internet untuk memperoleh bahan yang berhubungan dengan pembahasan yang dibuat.

Metode pengembangan perangkat lunak Metode Waterfall (Air terjun) Menurut (A.S., Rosa dan M. Shalahuddin, 2016, p. 28) Model air terjun (waterfall) adalah "Model sekuensial linier (sequential Linear) atau alur hidup klasik (classic life cycle). Model air terjun menyediakan pendekatan alur hidup perangkat lunak secara sekuential atau terurut dimulai dari analisis, desain, pengkodean, pengujian dan tahap pendukung (support)". Berikut adalah model air terjun yang dapat dilihat pada Gambar1.

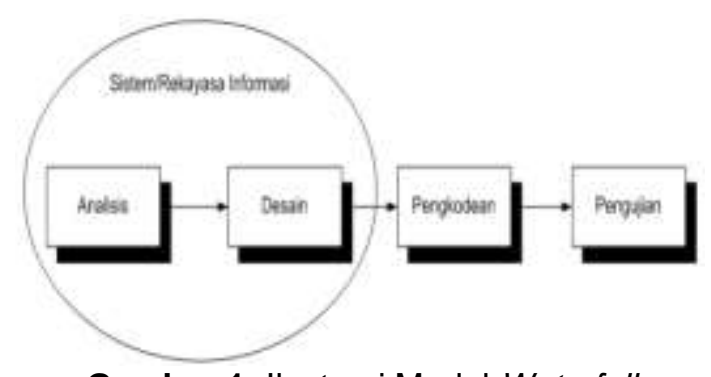

Gambar 1. Ilustrasi Model Waterfall

Sumber: (A.S., Rosa dan M. Shalahuddin, 2016, p. 29)

\section{Hasil Dan Pembahasan}

Pada pembuatan aplikasi ini penulis melakukan tahapan penyelesaian masalah sebaigai berikut

a. Melakukan rancangan dan konsep aplikasi

Dalam melakukan perancangan dan konsep aplikasi penulis mencari referensi dari berbagai sumber. Membandingkan dengan aplikasi yang serupa untuk mencari perbedaannya.

b. Mencari materi untuk konten

Pembelajrannya. Materi di dalam aplikasi pun sudah penulis rangkum demi terciptanya keefektifan saat mempelajari huruf Hangeul.

Mendesain aplikasi yang nyaman untuk penggunaannya. Penulis juga mendesain tampilan background halaman menu utama dengan gambar salah satu istana Korea Selatan yaitu istana Gyeongbok Gung.

c. Membuat aplikasi pembelajaran huruf hangeul. Aplikasi ini penulis beri nama Belajar Huruf Hangeul. Merealiasasikan rancangan dan konsep yang telah dibuat serta memasukan materi yang telah di kumpulkan.

d. Setelah aplikasi selesai dibuat penulis melakukan pengujian terhadap aplikasi yang dibuat apakah sesuai dengan konsep yang dibuat dan berjalan dengan baik. Jika belum sesuai penulis melakukan perbaikan terhadap aplikasi tersebut.

Kebutuhan fungsional Aplikasi ini terdiri dari beberapa fungsi utama yang saling berhubungan dan saling mendukung satu sama lain yang meliputi sebagai berikut :

1. User dapat melihat daftar huruf hangeul dan mendengarkan bunyi setiap huruf

2. User dapat berlatih dengan memainkan game kuis tebak huruf

3. User dapat melihat hasil dari kuis yang telah diselesaikan 
4. User dapat menghapus semua data hasil perolehan nilai pada setiap levelnya

a. Spesifikasi Perangkat Keras

- Pengembangan:

1) Display 14 inch

2) Prosesor Intel Celeron @1.60 GHz

3) Intel HD Graphics Family

4) Memori (RAM) 2GB

5) Harddisk 200GB

6) Mouse

7) Keyboard

- Pengguna:

1) Memori RAM minimal $1 G B$

2) ROM 4GB

b. Spesifikasi Perangkat Lunak

- Pengembangan:

1) Sistem Operasi Windows 7

2) Unity 5.6.7.f1

- Pengguna:

1) OS Android Minimal Jellybean 4.1

c. Struktur Navigasi

penulis menggunakan struktur navigasi campuran Berikut adalah struktur navigasi pada aplikasi Belajar Huruf Hangeul bisa dilihat pada Gambar 2.

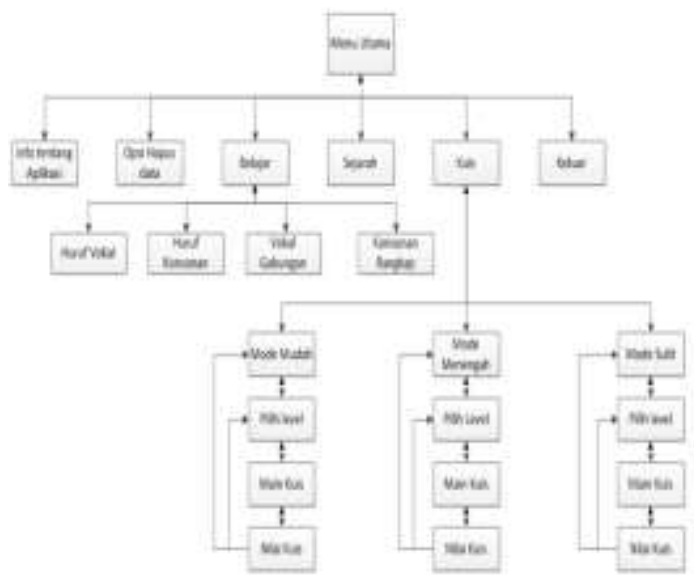

Gambar 2. Struktur Navigasi

\section{Implementasi}

Implementasi adalah hasil nyata dari pembuatan program Aplikasi. Pada implementasi aplikasi penulis sudah melakukan screenshot pada tampilan asli Aplikasi Belajar Huruf Hangeul yang sudah di Build dan berbentuk sebuah apk.

\section{Halaman Menu Utama}

Halaman ini merupakan halaman utama aplikasi belajar huruf hangeul, terdapat beberapa menu untuk menampilkan suatu fungsi dari setiap menunya. Halaman menu utama dapat dilihat pada Gambar 3.

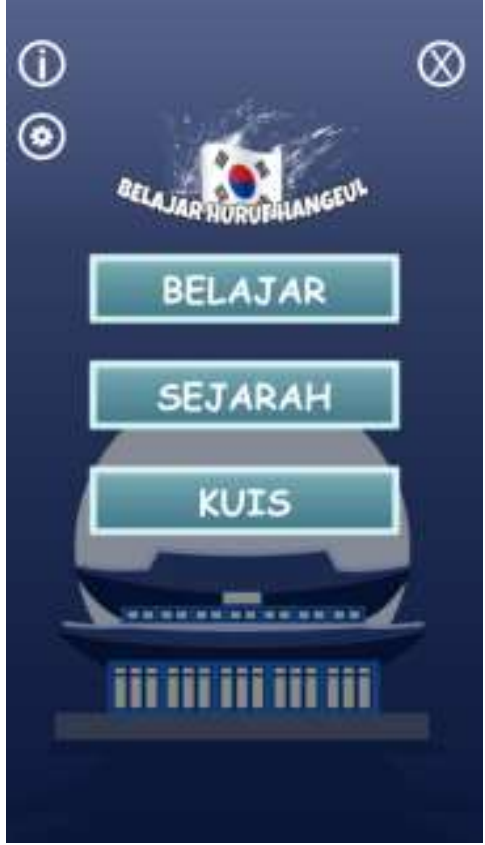

Gambar 3. Implementasi Halaman Menu Utama

\section{Halaman Informasi tentang Aplikasi}

Halaman ini berisi tentang informasi seputar aplikasi belajar huruf hangeul. Halaman Informasi Tentang Aplikasi dapat dilihat pada Gambar 4.

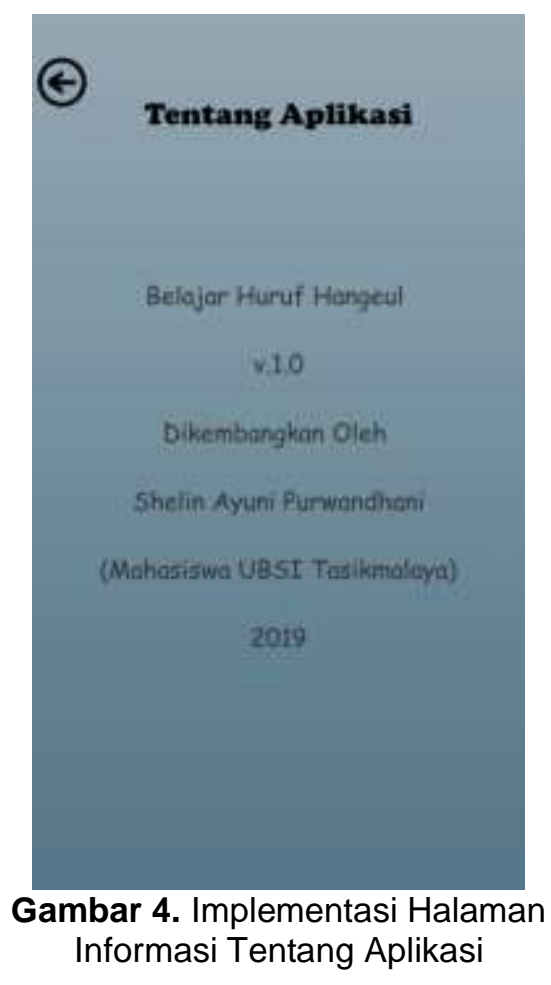

\section{Halaman Pengaturan}

Halaman ini merupakan halaman untuk mereset semua data pada aplikasi belajar 
huruf hangeul. Halaman Pengaturan dapat dilihat pada Gambar 5.

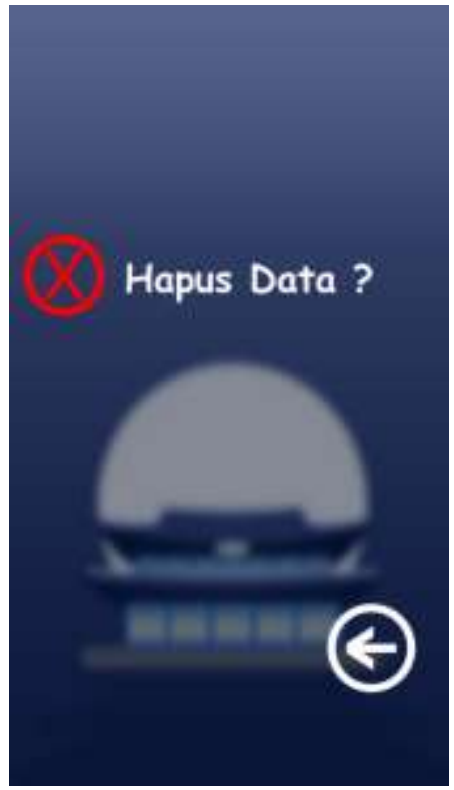

Gambar 5. Implementasi Halaman Pengaturan

\section{Halaman Belajar}

Halaman ini merupakan halaman untuk memilih jenis huruf yang akan di pelajari. Halaman Belajar dapat dilihat pada Gambar 6.

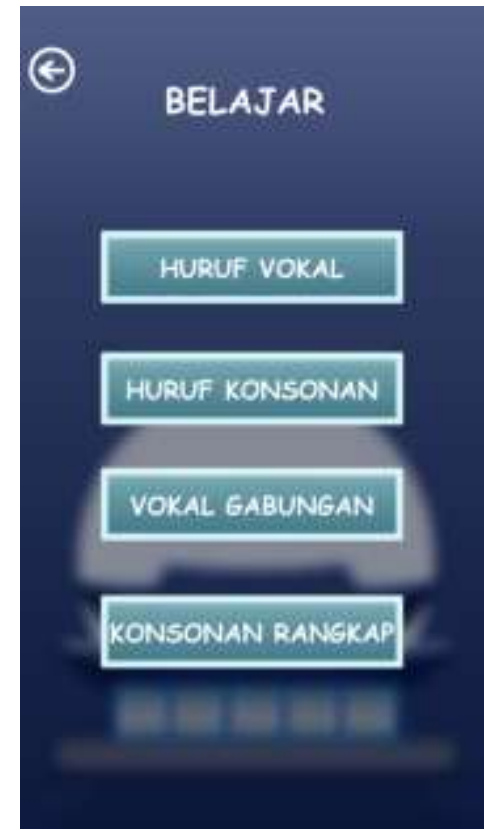

Gambar 6. Implementasi Halaman

$$
\text { Belajar }
$$

\section{Halaman Sejarah}

Halaman ini merupakan halaman untuk belajar sejarah tentang huruf hangeul,
Halaman Sejarah dapat dilihat pada Gambar 7.

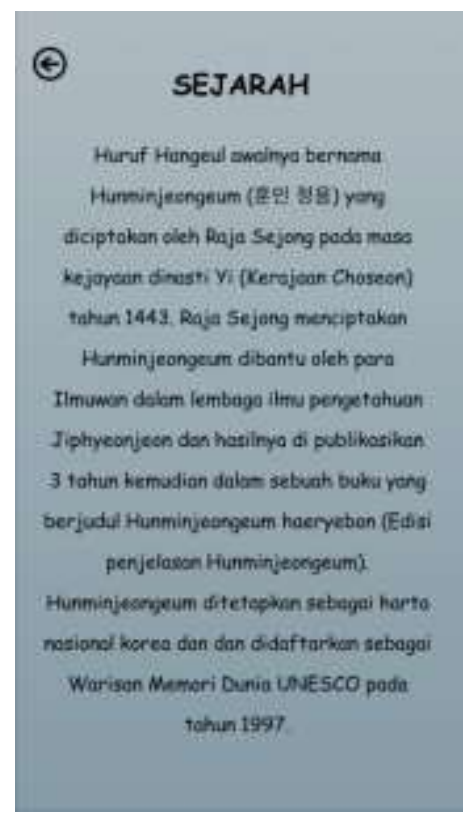

Gambar 7. Implementasi Halaman Sejarah

\section{Halaman Materi Huruf}

Halaman ini merupakan halaman untuk belajar huruf hangeul, setiap huruf dapat mengeluarkan suara penyebutannya saat mengklik tombol suara, pada bagian bawah terdapat pula contoh penulisan hurufnya. Halaman Materi Huruf dapat dilihat pada Gambar 8.

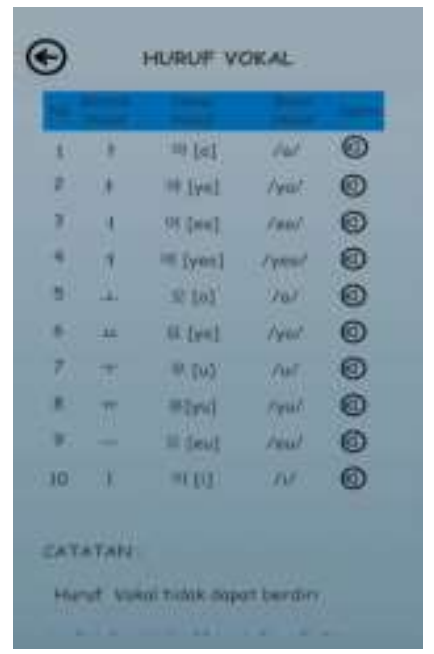

Gambar 8. Implementasi Halaman Materi Huruf

\section{Halaman Kuis}

Halaman ini merupakan halaman untuk memilih mode tingkat kesulitan permainan kuis huruf hangeul. Halaman Kuis dapat dilihat pada Gambar 9. 


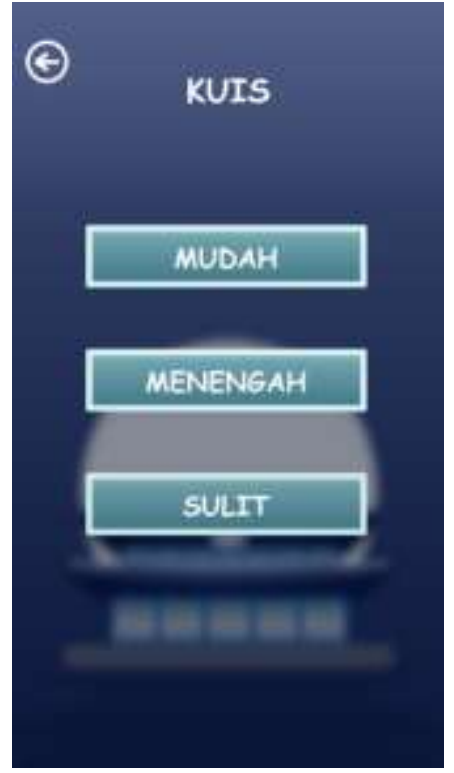

Gambar 9. Implementasi Halaman Kuis

\section{Halaman Mode Kuis}

Halaman ini merupakan halaman untuk memilih level dari mode kuis pada permainan kuis huruf hangeul, setiap mode terdapat 10 level permainan kuis. Halaman Mode Kuis dapat dilihat pada Gambar 10.

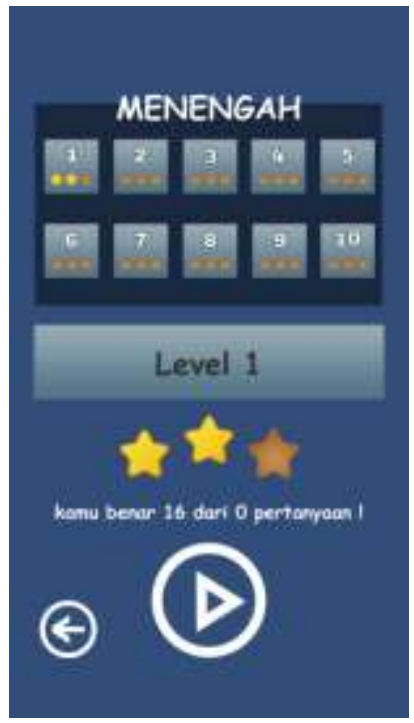

Gambar 10. Implementasi Halaman Mode Kuis

\section{Halaman Main Kuis}

Halaman ini merupakan halaman untuk permainan kuis, berisi pertanyaan dan terdapat empat pilihan ganda untuk jawabannya, pada halaman main kuis ini pertanyaannya hanya mengulas semua jenis huruf hangeul yang telah dipelajari, terdapat juga tombol pause yang berisi tombol untuk me-restart, kembali ke halaman mode kuis saat ditengah permainan dan me-resume kembali permainan. Halaman Main Kuis dapat dilihat pada Gambar 11

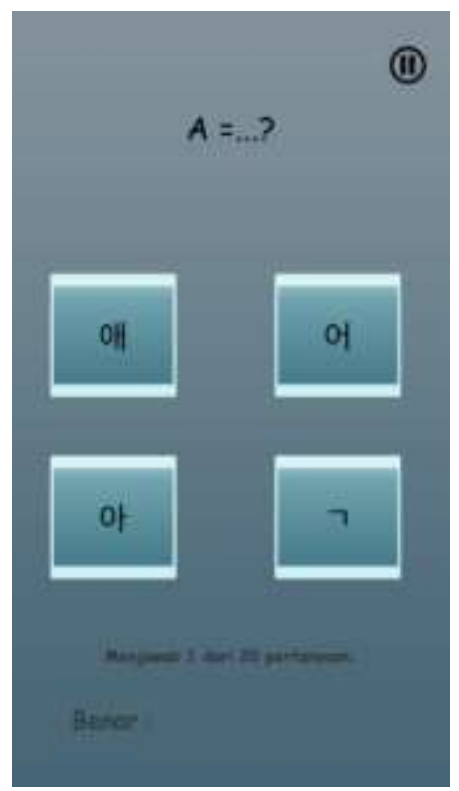

Gambar 11. Implementasi Halaman Main Kuis

\section{Halaman Hasil Nilai Kuis}

Halaman ini merupakan halaman untuk menampilkan hasil nilai perolehan bintang dari kuis pada saat kuis telah terselesaikan, terdapat tombol untuk kembali ke halaman pilih mode, kembali ke menu pilih level dan mengulang permainan. Halaman Hasil Nilai Kuis dapat dilihat pada Gambar 12.

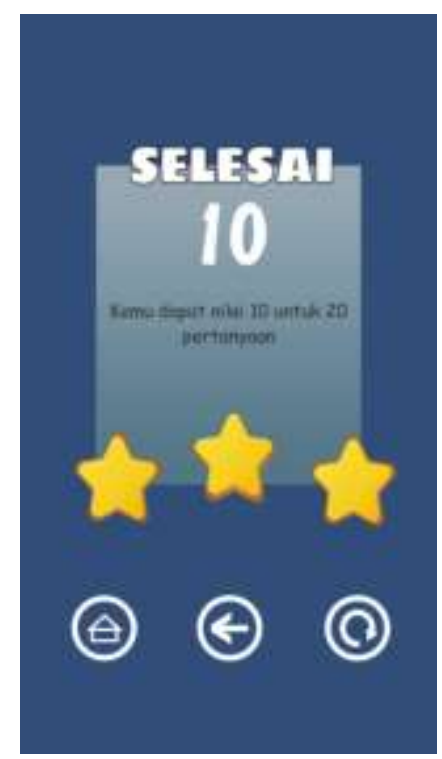

Gambar 12. Implementasi Halaman Hasil Nilai Kuis 


\section{Kesimpulan}

Berdasarkan uraian dari bab sebelumnya dapat ditarik kesimpulan bahwa Aplikasi ini dapat menarik minat pengguna untuk belajar huruf hangeul secara otodidak. Pembelajaran lebih efektif dan menyenangkan dengan adanya fitur kuis.

Aplikasi ini membahas tentang pembelajaran huruf hangeul jenis-jenis huruf,dan cara membacanya. Memudahkan pengguna dalam melafalkan huruf karena di dukung dengan audio pelafalan tiap hurufnya.

\section{Referensi}

A.S., Rosa dan M. Shalahuddin. (2016). Rekayasa Perangkat Lunak Terstruktur dan Berorientasi Objek. Bandung: Informatika Bandung.

Kurniawan., Andry. (2014). Rekayasa Perangkat Lunak Aplikasi Penjualan Pada

Toko Story Time Factory Outlet Menggunakan Pemrograman JAVA, Hal 3. Universitas Andalas.

Gani, Akbar \& Marlinda, Linda. (2017). Aplikasi Pembelajaran Trigonometri
Berbasis Shuffle. Jurnal Android Menggunakan Algoritma Fisher Yates Teknik Komputer Vol. III, No.2, 115. Diambil dari http://ejournal.bsi.ac.id/ ejurnal/index.php/jtk/article/view/2216

Herianto, E., Nurwanti, E.K., \& Andayati, D. (2018). Skripsi Implementasi Kecerdasan Buatan Pada Game Menggunakan Metode Pathfinding Dengan Game Engine Unity3d. Jurnal SCRIPT Vol. 5 No. 2, 57. Diambil dari https://ejournal.akprind.ac.id/index.php/ script/article/view/641

Maarif, V., Widodo, A.E., \& Wibowo, D.Y. (2017). Aplikasi Tes IQ Berbasis Android. IJSE - Indonesian Journal on Software Engineering Volume 3 No 2 - 2017, 37-38. Diambil dari http://ejournal.bsi.ac.id/ejurnal/index.ph p/ijse/article/view/2820/1841

Andre, Pentrus. (2014). Macam-macam Struktur Navigasi Pada Website. Diambil dari https://www.andre.web.id/strukturnavigasi-website/ (24 Juni 2019).

Korea Foundation, (2018). Jumlah Fans Hallyu Melebihi 70 juta Orang. Diambil dari (12 Agustus 2019). 